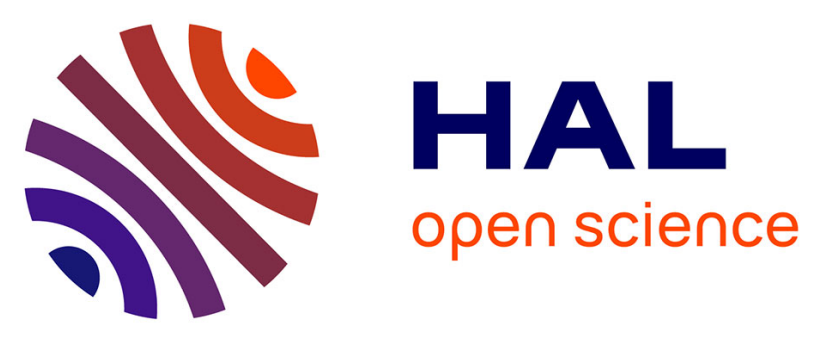

\title{
Asymmetric synthesis of the two enantiomers of $\beta$-phosphorus-containing- $\alpha$-Amino Acids via hydrophosphinylation and hydrophosphonylation of chiral Ni(II)-complexes
}

Yoshinori Tokairin, Hiroyuki Konno, Angéline Noireau, Caroline West, Hiroki

Moriwaki, Vadim A Soloshonok, Cyril Nicolas, Isabelle Gillaizeau

\section{To cite this version:}

Yoshinori Tokairin, Hiroyuki Konno, Angéline Noireau, Caroline West, Hiroki Moriwaki, et al.. Asymmetric synthesis of the two enantiomers of $\beta$-phosphorus-containing- $\alpha$-Amino Acids via hydrophosphinylation and hydrophosphonylation of chiral Ni(II)-complexes. Organic Chemistry Frontiers, 2021, 8 (1-4), 10.1039/D1QO00159K . hal-03359971

\section{HAL Id: hal-03359971 \\ https://hal.science/hal-03359971}

Submitted on 30 Sep 2021

HAL is a multi-disciplinary open access archive for the deposit and dissemination of scientific research documents, whether they are published or not. The documents may come from teaching and research institutions in France or abroad, or from public or private research centers.
L'archive ouverte pluridisciplinaire $\mathbf{H A L}$, est destinée au dépôt et à la diffusion de documents scientifiques de niveau recherche, publiés ou non, émanant des établissements d'enseignement et de recherche français ou étrangers, des laboratoires publics ou privés. 
Received 00th January 20xx, Accepted 00th January 20xx

DOI: $10.1039 / \times 0 \times x 00000 x$

\title{
Asymmetric Synthesis of the Two Enantiomers of $\beta$-Phosphorus- containing $\alpha$-Amino Acids via Hydrophosphinylation and Hydrophosphonylation of Chiral Ni(II)-Complexes
}

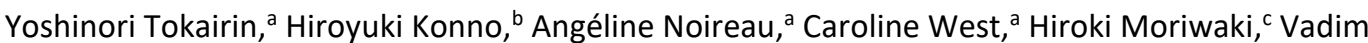
A. Soloshonok, ${ }^{\text {d,e }}$ Cyril Nicolas*a and Isabelle Gillaizeau*a

A new approach for the asymmetric synthesis of the two enantiomers of $\beta$-phosphorus-containing $\alpha$-amino acids was developed via Michael addition of secondary phosphine oxides and dialkyl phosphites to chiral Ni (II)-complexes of a dehydroalanineSchiff base.

Organophosphorus derivatives are widely found in natural products, pharmaceuticals, ligands and functional materials. ${ }^{1}$ In particular, phosphorus-containing $\alpha$-amino acids are important classes of tailor-made compounds that have gained considerable attention in peptide design strategies as they enhance stability towards protease degradation and modulate bioactivity. They can also be used for labelling purposes. ${ }^{2}$ Notably, it was shown that phosphonic analogues of aminodicarboxylic acids act as group-selective agonists or antagonists for the $\mathrm{N}$-methyl-D-aspartate (NMDA) receptor site. Indeed, aminophosphonic acids such as AP-3, AP-4, AP-5 and AP-7 have been demonstrated to be particularly potent when evaluated for the treatment of central nervous system disorders (Figure 1). ${ }^{3}$

Given the prominence of phosphorus-containing $\alpha$-amino acids, various P-sources, such as dialkyl/diaryl phosphines, $\mathrm{H}$ phosphonates, or secondary phosphine oxides have been used for $\mathrm{C}-\mathrm{P}$ bond constructions. ${ }^{4}$ However, most of the synthetic methods used so far are based on reactions of air-sensitive (organometallic) reagents or phosphide salts which suffer from limited scope, laborious purification, and low yields. Furthermore, these reactions have typically been catalysed by strong bases, radical initiators, or transition metal catalysts. ${ }^{4}$ To address this aspect, phospha-Michael addition, ${ }^{5}$ i.e. the

\footnotetext{
a. Institute of Organic and Analytical Chemistry, ICOA UMR 7311 CNRS, Universite d'Orléans, rue de Chartres, 45100 Orléans, France.

E-mail: Isabelle.gillaizeau@univ-orleans.fr.

b. Department of Biochemical Engineering, Graduate School of Science and Technology, Yamagata University, Yonezawa, Yamagata 992-8510, Japan. Hamari Chemicals Ltd., 1-19-40 Nankokita Suminoe-ku, Osaka 559-0034, Japan. d. Department of Organic Chemistry I, Faculty of Chemistry, University of Basque County UPV/EHU, Paseo Manuel Lardizabal 3, 20018 San Sebastian, Spain. e. IKERBASQUE, Basque Foundation for Science, Alameda Urquijo 36-5, Plaza Bizkaia, 48011 Bilbao, Spain.

†Electronic Supplementary Information (ESI) available: General experimental information and procedure for product synthesis, full characterization data, ${ }^{1} \mathrm{H}$ and ${ }^{13}$ C NMR spectra. CCDC 2036929. CCDC 2036930. See DOI: 10.1039/x0xx00000x
}

addition of P-nucleophiles to an acceptor-substituted alkene or alkyne, certainly represents one of the most versatile, atomeconomical and straightforward approaches.

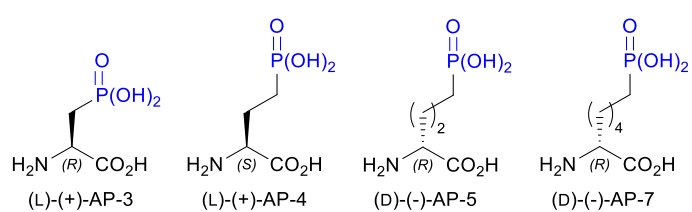

Figure 1. Pharmaceutically important phosphorous-containing $\alpha$-amino acids.

However, even though the asymmetric synthesis of phosphorus-containing amino acids has been intensely pursued in recent years, ${ }^{4 b}$ to the best of our knowledge, the stereoselective Michael addition of phosphide anions to create new phosphorus-carbon bonds remains little explored to date. ${ }^{4 b}$ Importantly, Feringa and co-workers described the conjugate addition of lithiodiphenylphosphine to optically active butenolide synthon, $(5 R)$-menthyloxy-2[5H]-furanone, leading to enantiopure S,S-CHIRAPOS. ${ }^{6}$ Wang and co-workers also achieved the asymmetric addition of dialkylphosphine oxides to enones with high enantioselectivity by using $\mathrm{Et}_{2} \mathrm{Zn}$ as a base and dinuclear metal-ProPhenol catalysts. ${ }^{7} \mathrm{~A}$ stereoselective Michael addition of $\mathrm{P}(\mathrm{X})-\mathrm{H}$-type nucleophiles to cyclohexen-1-ylphosphine oxide was also described by Stankevič and co-workers. ${ }^{8}$ Another point probably worthy of note is that the simple asymmetric activation of $P(X)-H$ moieties via deprotonation with a basic catalyst remains an inaccessible strategy due to the lack of suitable non-racemic chiral molecular entities that exert a sufficiently strong basicity, thus neglecting the intrinsic reactivity of the phosphite form. ${ }^{7}$

In this context and despite significant advances in this field, the stereoselective phospha-Michael reaction on activated alkenes remains a highly desirable alternative. As a consequence, and relying on our long-standing interest in tailormade amino acids (AAs), including phosphorus-containing derivatives, ${ }^{9,10}$ we envisioned performing the asymmetric synthesis of $\beta$-phosphorus-containing $\alpha$-amino acids by taking advantage of chiral trichloro-substituted $\mathrm{Ni}(\mathrm{II})$-complexes of dehydroalanine Schiff bases. ${ }^{11}$ An excellent diastereoselectivity was observed upon hydrophosphonylation or 
hydrophosphinylation of the chiral enone (S)-1a or (R)-1a, further providing very simple access to a wide range of enantiopure $\beta$-phosphono- and $\beta$-phosphino- $\alpha$-amino acid derivatives through subsequent disassembly and reconstruction of the chiral Ni(II)-platform.

At the outset of the study, synthesis of the requisite optically pure $\mathrm{Ni}(\mathrm{II})$-dehydroalanine complex, ${ }^{12}[(R)-\mathbf{1 a}$ and $(S)-1 \mathbf{a}]$ and phosphine oxide reagents (2) was performed according to literature procedures. It is worth noting that complexes of type 1 were previously shown to exhibit operational simplicity and an exquisite potential for large-scale applications. ${ }^{12,13}$ In addition, the excellent levels of the asymmetric induction during their additions with various $\mathrm{O}-, \mathrm{N}$ - and $\mathrm{RCF}_{2}$ - nucleophiles were correlated with the chlorine degree and substitution pattern of the chiral auxiliary. ${ }^{12,13}$ It should be emphasized that reactions of the corresponding chiral $\mathrm{Ni}(\mathrm{II})$ complexes of dehydroalanine still remain the least well studied area. ${ }^{13 a}$

Table 1. Optimization of the reaction conditions. ${ }^{\mathrm{a}, \mathrm{b}}$

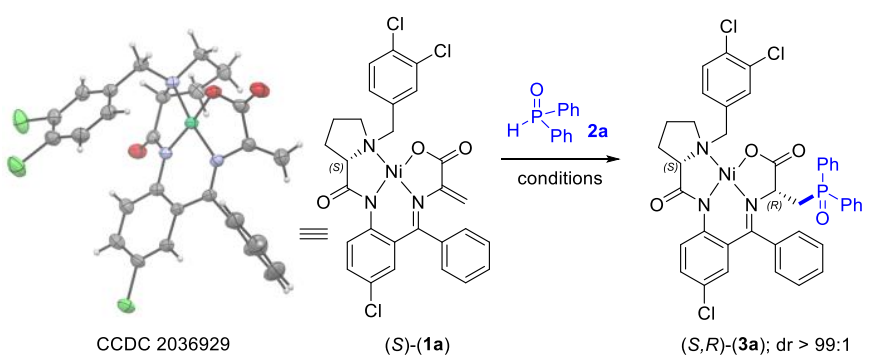

\begin{tabular}{|c|c|c|c|c|c|c|c|}
\hline Entry & $\begin{array}{c}\mathrm{K}_{2} \mathrm{CO}_{3} \\
\text { (eq.) }\end{array}$ & $\begin{array}{c}2 a \\
\text { (eq.) }\end{array}$ & $\mathrm{t}\left({ }^{\circ} \mathrm{C}\right)$ & $\begin{array}{c}\text { Time } \\
\text { (h) }\end{array}$ & Solvent & $\begin{array}{c}3 a \\
(\%)^{c}\end{array}$ & $\begin{array}{c}1 a \\
(\%)^{c}\end{array}$ \\
\hline 1 & 0.25 & 2.0 & $\mathrm{rt}$ & 24 & $\mathrm{CH}_{3} \mathrm{CN}$ & 43 & 40 \\
\hline 2 & 0.25 & 2.0 & 60 & 4 & $\mathrm{CH}_{3} \mathrm{CN}$ & 73 & 0 \\
\hline 3 & 1.0 & 2.0 & 60 & 4 & $\mathrm{CH}_{3} \mathrm{CN}$ & 65 & 0 \\
\hline 4 & 0.25 & 1.5 & 60 & 4 & $\mathrm{CH}_{3} \mathrm{CN}$ & 89 & 0 \\
\hline 5 & 0.25 & 1.0 & 60 & 4 & $\mathrm{CH}_{3} \mathrm{CN}$ & 79 & 5 \\
\hline 6 & 0.25 & 1.5 & 60 & 4 & $\mathrm{CH}_{2} \mathrm{Cl}_{2}$ & 44 & 52 \\
\hline 7 & 0.25 & 1.5 & 60 & 4 & THF & 71 & 5 \\
\hline 8 & 0 & 1.5 & 60 & 4 & $\mathrm{CH}_{3} \mathrm{CN}$ & 65 & 34 \\
\hline $9^{d}$ & 0.25 & 1.5 & 60 & 4 & $\mathrm{CH}_{3} \mathrm{CN}$ & 73 & 0 \\
\hline
\end{tabular}

a Reaction conditions: (S)-(1a) (164 $\mu \mathrm{mol}, 1$ eq.), 2a (246 $\mu \mathrm{mol}, 1.5$ eq.), $\mathrm{K}_{2} \mathrm{CO}_{3}$ (41 $\mu \mathrm{mol}, 0.25$ eq.), $\mathrm{CH}_{3} \mathrm{CN}(5 \mathrm{~mL})$, heating under air atmosphere in a sealed tube for 4 h. ${ }^{b}$ The diastereomeric ratio was determined by ${ }^{1} \mathrm{H}$ and ${ }^{31} \mathrm{P}$ NMR analysis of the crude product. ${ }^{\mathrm{c}}$ Isolated yield. ${ }^{\mathrm{d}}$ Reaction performed on a $3.0 \mathrm{mmol}$ (ca. $1.8 \mathrm{~g}$ ) scale of $(S)-(1 a)$.

Complex (S)-1a, (CCDC 2036929) and diphenylphosphine oxide 2a were thus selected as model substrates and the conditions for the phospha-Michael addition reaction were optimized. The results are summarized in Table 1 . The Michael addition of $\mathrm{R}_{2} \mathrm{P}(\mathrm{O}) \mathrm{H}$ to simple activated alkenes is usually conducted under basic conditions in polar solvents - either in the presence of a soft basic catalyst ( $\mathrm{DBU}, \mathrm{K}_{2} \mathrm{CO}_{3}$, etc.,) or by using a strong base (e.g., $n \mathrm{BuLi}, \mathrm{NaH}$ ) in stoichiometric amount. ${ }^{14,15}$ Noteworthy, the $\mathrm{R}_{2} \mathrm{PH} / \mathrm{K}_{2} \mathrm{CO}_{3}$ heterogeneous system which provides the phosphide anion only at a low concentration might preclude extensive racemization at the $\alpha$-carbon atom of the newly generated chiral phosphorus adducts. To our delight, in the presence of 0.25 equivalent of $\mathrm{K}_{2} \mathrm{CO}_{3}$ as a base in acetonitrile at room temperature during $24 \mathrm{~h}$, the desired phosphine oxide intermediate $(S, R)$-3a was obtained in moderate yield $(43 \%)$, as a single diastereomer (d.r. > 99:1) (entry 1). Importantly, no epimerization of the newly formed stereocenter could be detected through subsequent purification by $\mathrm{SiO}_{2}$ chromatography and over prolonged storage under argon atmosphere at/or below $4{ }^{\circ} \mathrm{C}$. Aiming to further improve the product yield (entries 2-5), the reaction temperature was increased, and the screening of the number of equivalents of $\mathrm{K}_{2} \mathrm{CO}_{3}$ and of the phosphine oxide $2 \mathrm{a}$ were carried out. A series of common organic solvents was also examined, revealing that acetonitrile is best suited for this transformation (entries 6-7). A control experiment was then conducted without any base producing $(S, R)$-3a in moderate yield (65\%) along with $34 \%$ of recovered starting material (entry 8 ). Interestingly, this outcome unveils significant information: a base is not essential to promote the phosphorus bond formation, thus providing alternatives for base-sensitive phosphines. Having successfully determined the optimal conditions for the $\mathrm{P}(\mathrm{O})-\mathrm{H}$ bond addition reaction (entry 4), a gram-scale synthesis of (S)-1 was performed in high diastereoselectivity to deliver $(S, R)$-3a without a noticeable decrease in the yield and with recovery of the chiral ligand (entry 9).

As outlined in Scheme 2, the reaction scope was thereafter investigated with a range of secondary phosphine oxides $\mathbf{2} \mathbf{b}-\mathbf{h}$ and dialkyl phosphites $\mathbf{2} \mathbf{i}-\mathbf{m}$. The nucleophilicity of these reagents was important in ensuring successful reactivity. We observed that the electronic properties and substitution pattern of the diaryl phosphine oxide reagents did not alter the efficacy of the addition process even with slightly electronwithdrawing groups, such as $p-\mathrm{F}(\mathbf{3 g})$ and $p-\mathrm{CF}_{3}(\mathbf{3 h})$. The corresponding Schiff base products $3 \mathbf{b}$-d featuring 2-Me, 3,5diMe and 4-t-Bu on the phenyl group were obtained in good yields (e.g., 63-79 \%). Naphtyl- and benzyl-phosphinyl derivatives were also allowed, giving $\mathbf{3} \mathbf{f}$ and $\mathbf{3 e}$ in moderate (41\%) to good yields (63\%) respectively. Of note, the Schiff base products obtained $(S, R)$-(3a-h) were all isolated as single diastereomers (d. $r>99: 1$ ).

With these promising results in hand, we turned our attention toward the addition of dialkyl phosphites $\mathbf{2} \mathbf{i}-\mathbf{m}$ to the chiral enone (S)-1a under standard conditions. In this case, high diastereoselectivities (d.r > 99:1) were also obtained, but with significantly lower yields. The reaction efficiency was boosted through the use of $\mathrm{Cs}_{2} \mathrm{CO}_{3}$ instead of $\mathrm{K}_{2} \mathrm{CO}_{3}$ as a base, which provided $(S, R)-\mathbf{3 i}-\mathbf{m}$ in moderate to good yields (35-85\%).

The multi-functionality present in the product provides a further opportunity for post-functionalization. The disassembly of the $\mathrm{Ni}(I I)$ complexes $(S, R)$-3a and $(S, R)$-3k (as presented in Scheme 3 ) was thus performed next, under standard conditions by treatment with $4 \mathrm{~N}$ aq. $\mathrm{HCl}$ in THF (1:4) for 10 minutes at ambient temperature. ${ }^{16}$ The red coloured mixture gradually changed to a green solution, indicating disassembly of the starting $(S, R)$-3a or $(S, R)$-3k complex and formation of $\mathrm{NiCl}_{2}$. The mixture was diluted $\left(\mathrm{H}_{2} \mathrm{O}\right)$ and the aqueous phase was extracted with EtOAc to recycle the chiral dehydroalanine Schiff base ligand which was obtained as a hydrochloric salt and recovered with $75 \%$ yield. The aqueous phase was then treated with EDTA 
to chelate the $\mathrm{Ni}(\mathrm{II})$ ions and protection of the hydrochloric salt of the in situ generated amino acid was performed using $\mathrm{Boc}_{2} \mathrm{O}$ in a mixture of dioxane: $\mathrm{H}_{2} \mathrm{O}$ at ambient temperature in the presence of $\mathrm{NaHCO}_{3}$. Compounds $(R)-4 \mathrm{a}(60 \%)$ and $(R)-\mathbf{4 k}(49 \%)$ were respectively obtained in good and moderate yields with 96\% enantiomeric purity (SFC analysis, see SI).

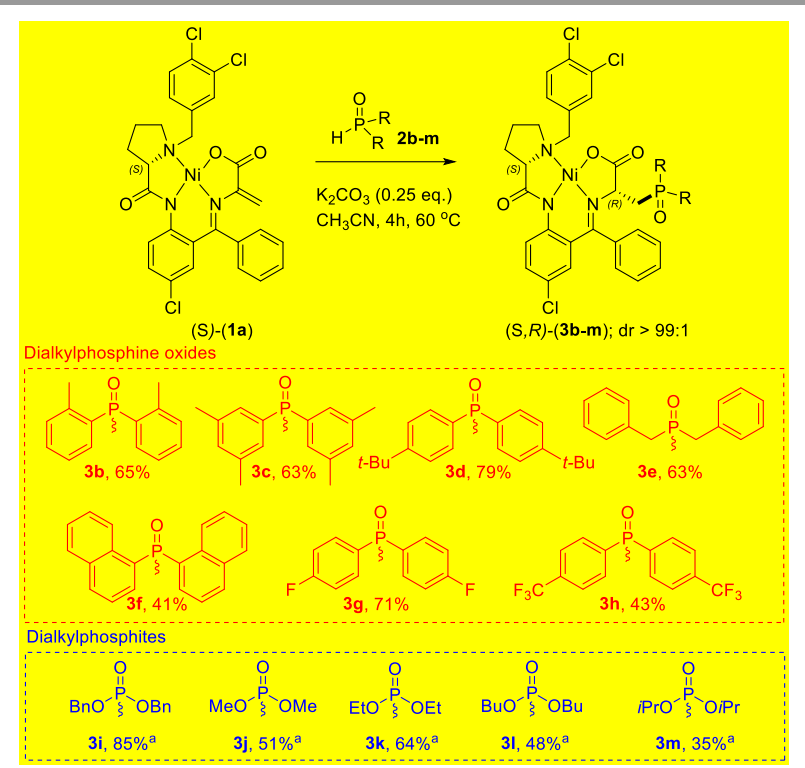

Scheme 2. Phospha-Michael addition of secondary phosphine oxides $(R=A r) \mathbf{2} \mathbf{b}-\mathbf{h}$ and dialkyl phosphites ( $\mathrm{R}=\mathrm{OAlk}$ ) $\mathbf{2 i -} \mathbf{m}$ to dehydroalanine complex (S)-1a. ${ }^{a} \mathrm{CsCO}_{3}$ (0.25 eq.) was used instead of $\mathrm{K}_{2} \mathrm{CO}_{3}$.

Taking advantage of the high crystallinity of the aminophosphonate derivative $(R)-\mathbf{4 k}$, single crystals were then grown from a solution in dichloromethane at ambient temperature to allow absolute configuration determination of compound $(R)$-4k by X-ray spectroscopy (SI) (CCDC 2036930).

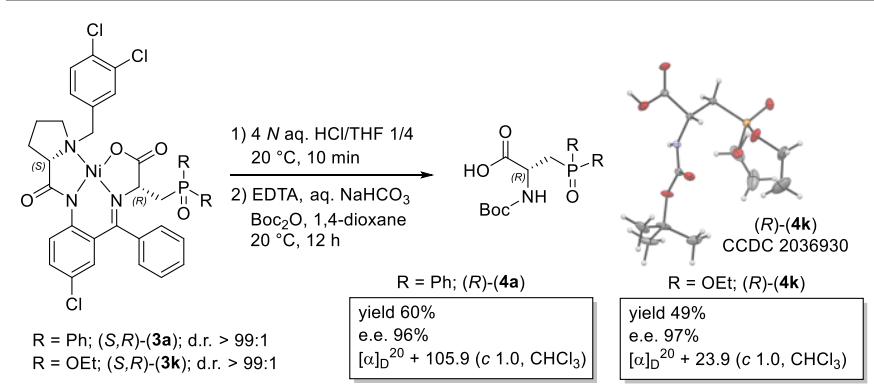

Scheme 3. Asymmetric Synthesis of Compounds $(R)-\mathbf{4 a}$ and $(R)-\mathbf{4 k}$ Through Disassembly of Chiral Complex $(S, R)-\mathbf{3 a}$ and $(S, R)-\mathbf{3 k}$.

It is interesting to note that this stereochemical outcome could be reasonably rationalized from the crystallographic structure analysis of the $\mathrm{Ni}$ (II) complex of the Schiff base of dehydroalanine (S)-1a. Indeed, as outlined in Figure 2 and the $\mathrm{SI},(S)$-1a provides optimal parallel displaced type of aromatic interactions between the o-amino-benzophenone moiety, featuring a $p$-chlorine atom, and the Pro $N$-benzyl ring (Fig. 2. A.1. and 2.A.2.). We have observed similar results from the crystallographic analysis of the corresponding $\mathrm{Gly} \mathrm{Ni}(\mathrm{II})$ complex. ${ }^{17}$ These interactions can be defined as a mixed case of parallel displaced and T-shaped or edge-to-face electrostatic aromatic interactions. This striking evidence has hence a strong impact on the stereochemistry of the chelate rings around the $\mathrm{Ni}(I I)$, which accordingly adopt bent structures (Fig. 2.B.1. and 2.B.2.) and an axial chirality along the Ni-N (Schiff base) and Ni$\mathrm{N}$ (amide) bonds.

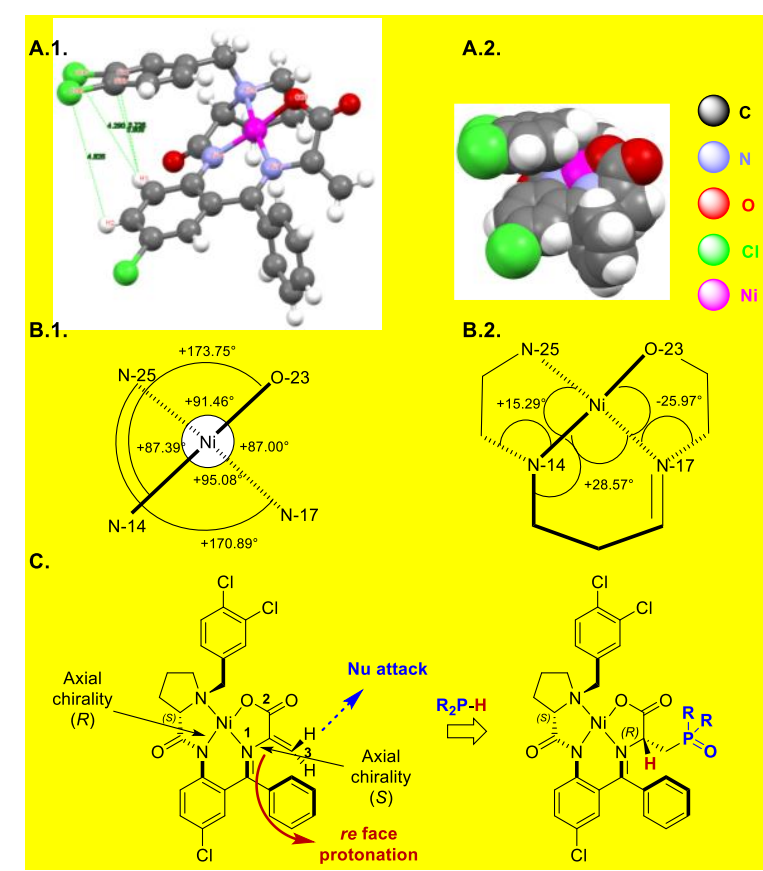

Figure 2. Data on dehydroAla Schiff base complex (S)-1a: A.1. Ball and stick crystallographic structure; A.2. Spacefill crystallographic structure; B.1. Deviation from the planarity of the $\mathrm{Ni}(\mathrm{II})$ coordination sphere. B.2. Dihedral angles of the chelate rings around the $\mathrm{Ni}(\mathrm{II})$. C. Axial chirality of the chelate rings and rationale for the scalemic formation of $\beta$-phosphorus adducts.

The absolute configuration of these chiral axes is relayed to the 3D rearrangement of the phenyl group and thus to the way of pyramidalization and of protonation (i.e., by the re face) of the forthcoming chiral carbon atom (Fig. 2.C.).

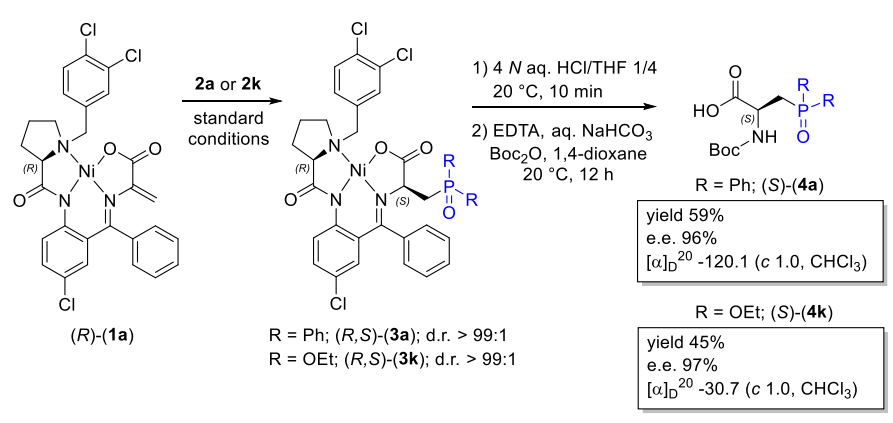

Scheme 4. Asymmetric Synthesis of Amino Acid Derivatives (S)-4a and (S)-4k

Remarkably, the asymmetric synthesis of the opposite enantiomers (S)-4a and (S)-4k was also smoothly achieved (see scheme 4) starting from the Ni(II) complex of the Schiff base of dehydroalanine $(R)$-1a using standard conditions. The entero derivatives (S)-4a and (S)-4k were obtained with the same stereoselectivities and similar overall yields (Scheme 4). 
In summary, we have achieved a general and new asymmetric approach for the synthesis of the two enantiomers of $\beta$ phosphorus-containing $\alpha$-amino acids. The key steps involve first a phospha-Michael addition of either a secondary phosphine oxides or dialkyl phosphites in the presence of a soft basic catalyst to chiral $\mathrm{Ni}$ (II)-complexes of dehydroalanine Schiff base leading to the corresponding Schiff base products with a high diastereomeric ratio followed by disassembly and then reconstruction of the chiral $\mathrm{Ni}(\mathrm{II})$-platform. Given the importance of $\beta$-phosphono $\alpha$-amino acids, and the lack of (catalytic) synthetic approaches that have been reported so far, this protocol appears as a method of choice for the preparation of tailor-made enantiopure $\alpha$-amino acids. Further studies on the use of the chiral auxiliary in diverse reactions are currently in progress.

\section{Conflicts of interest}

There are no conflicts to declare.

\section{Notes and references}

1 (a) R. E. Babine and S. L. Bender, Molecular Recognition of Protein-Ligand Complexes: Applications to Drug Design, Chem. Rev., 1997, 97, 1359-1472; (b) W. Tang and X. Zhang, New Chiral Phosphorus Ligands for Enantioselective Hydrogenation, Chem. Rev., 2003, 103, 3029-3070; (c) Y. Feng and J. K. Coward, Prodrug Forms of N-[(4-Deoxy-4-amino-10methyl)pteroyl]glutamate- $\gamma-[\psi \mathrm{P}(\mathrm{O})(\mathrm{OH})]$-glutarate, a Potent Inhibitor of Folylpoly- $\gamma$-glutamate Synthetase: Synthesis and Hydrolytic Stability, J. Med. Chem., 2006, 49, 770-788; (d) T. Baumgartner and R. Réau, Organophosphorus $\pi$-Conjugated Materials, Chem. Rev., 2006, 106, 4681-4727; corrigendum: Chem. Rev., 2007, 107, 303; (e) Y. Yang and J. K. Coward, Synthesis of $p$-Aminophenyl Aryl H-Phosphinic Acids and Esters via Cross-Coupling Reactions: Elaboration to Phosphinic Acid Pseudopeptide Analogues of Pteroyl Glutamic Acid and Related Antifolates, J. Org. Chem., 2007, 72, 5748-5758; (f) A. Boëdec, H. Sicard, J. Dessolin, G. Herbette, S. Ingoure, C. Raymond, C. Belmant and J.-L. Kraus, Synthesis and Biological Activity of Phosphonate Analogues and Geometric Isomers of the Highly Potent Phosphoantigen (E)-1-Hydroxy-2-methylbut-2-enyl 4-Diphosphate, J. Med. Chem., 2008, 51, 1747-1754; (g) D. W. Allen, Phosphines and related $\mathrm{C}-\mathrm{P}$ bonded compounds, Organophosphorus Chem. 2016, 45, 1-50; (h) V. P. Kukhar, V. A. Soloshonok and V. A. Solodenko, Asymmetric Synthesis of Phosphorus Analogs of Amino Acids, Phosphorus, Sulfur, and Silicon and the Relat. Elem. 1994, 92, 239-264; (j) K. V. Turcheniuk, V. P. Kukhar, G.V. Roeschenthaler, J. Luis Acena, V. A. Soloshonok and A. E. Sorochinsky, Recent advances in the synthesis of fluorinated aminophosphonates and aminophosphonic acids, RSC Adv. 2013, 3, 6693-6716.

2 For reviews on phosphorous-containing peptidomimetics, see: (a) V. P. Kukhar and H. R. Hudson, Aminophosphonic and Aminophosphinic Acids: Chemistry and Biological Activity, John Wiley \& Sons: Chichester, 2000; (b) M. Collinsová and J. Jirácek, Phosphinic Acid Compounds in Biochemistry, Biology and Medicine, Curr. Med. Chem., 2000, 7, 629-647; (c) A. Yiotakis, D. Georgiadis, M. Matziari, A. Makaritis and V. Dive, Phosphinic Peptides: Synthetic Approaches and Biochemical Evaluation as Zn-Metalloprotease Inhibitors, Curr. Org. Chem. 2004, 8, 1135-1158; (d) F. Palacios, C. Alonso and J. M. de los
Santos, Synthesis of $\beta$-Aminophosphonates and Phosphinates, Chem. Rev., 2005, 105, 899-932.

3 For selected publications see: (a) L. Turski, T. Klockgether, W. A. Turski, M. Schwarz and K.-H. Sontag, Blockade of excitatory neurotransmission in the globus pallidus induces rigidity and akinesia in the rat: implications for excitatory neurotransmission in pathogenesis of Parkinson's diseases, Brain Res., 1990, 512, 125-131; (b) Y. Yoneda and K. Ogita, [Current topics on glutamate receptors], Yakugaku Zasshi, 1991, 111, 329-344; (c) A. Nadlewska, H. Car, R. Wiśniewska, Z. Holy and K. Wiśniewski, Behavioral effects of D-AP7 in rats subjected to experimental hypoxia, Pol. J. Pharmacol., 2003, 55, 337-344; (d) H.-M. Zhang, S.-R. Chen and H.-L. Pan, Effects of activation of group III metabotropic glutamate receptors on spinal synaptic transmission in a rat model of neuropathic pain, Neuroscience, 2009, 158, 875-884; (e) R. G. M. Morris, NMDA receptors and memory encoding, Neuropharmacology, 2013, 74, 32; (f) S. Lopez, N. TurleLorenzo, F. Acher, E. De Leonibus, A. Mele and M. Amalric, Targeting Group III Metabotropic Glutamate Receptors Produces Complex Behavioral Effects in Rodent Models of Parkinson's Disease, J. Neurosci., 2007, 27, 6701-6711 and ref. cited therein; (g) K. V. Turcheniuk, K. O. Poliashko, V. P. Kukhar, A. B. Rozhenko, V. A. Soloshonok and A. E. Sorochinsky, Efficient asymmetric synthesis of trifluoromethylated $\beta$-aminophosphonates and their incorporation into dipeptides, Chem. Commun., 2012, 48, 11519-11521; (h) G.-V. Röschenthaler, V. P. Kukhar, I. B. Kulik, M. Y. Belik, A. E. Sorochinsky, E. B. Rusanov and V. A. Soloshonok, Asymmetric synthesis of phosphonotrifluoroalanine and its derivatives using $\mathrm{N}$-tertbutanesulfinyl imine derived from fluoral, Tetrahedron Lett., 2012, 53, 539-542.

4 (a) M. Arribata, F. Cavelier and E. Rémond, RSC Adv., 2020, 10 6678; (b) H.-Q. Cao, J.-K. Li, F.-G. Zhang, D. Cahard and J.-A. $\mathrm{Ma}$, Asymmetric Synthesis of Chiral Amino CarboxylicPhosphonic Acid Derivatives, Adv. Synth. Catal. 2020, 362, 688-729.

5 For reviews, see: (a) D. Enders, A. Saint-Dizier, M.-I., Lannou and A. Lenzen, The Phospha-Michael Addition in Organic Synthesis, Eur. J. Org. Chem., 2006, 29-49; (b) X. Lu, C. Zhang and Z. Xu, Reactions of Electron-Deficient Alkynes and Allenes under Phosphine Catalysis, Acc. Chem. Res., 2001, 34, 535544; (c) J. L. Methot and W. Roush, Nucleophilic Phosphine Organocatalysis, Adv. Synth. Catal., 2004, 346, 1035-1050; (d) Z. S. Greenberg and D. W. Stephan, Stoichiometric and catalytic activation of $\mathrm{P}-\mathrm{H}$ and $\mathrm{P}-\mathrm{P}$ bonds, Chem. Soc. Rev., 2008, 37, 1482-1489; (e) A. Y. Rulev, Recent advances in Michael addition of $\mathrm{H}$-phosphonates, RSC Adv., 2014, 4, 26002-26012.

6 J. F. G. A. Jansen and B. L. Feringa, Michael Addition of lithiodiphenylphosphine to menthyloxy-2[5H]furanone:enantioselective synthesis of S,S-CHIRAPOS, Tetrahedron Asymm. 1990, 1, 719-720.

7 D. Zhao, L. Mao, D. Yang and R. Wang, Zinc-Mediated Asymmetric Additions of Dialkylphosphine Oxides to $\alpha, \beta$ Unsaturated Ketones and $\mathrm{N}$-Sulfinylimines, J. Org. Chem., 2010, 75, 6756-6763.

8 M. Jaklińska, M. Cordier and M. Stankevič, Stereoselectivity of Michael Addition of $\mathrm{P}(\mathrm{X})-\mathrm{H}$-Type Nucleophiles to Cyclohexen1-ylphosphine Oxide: The Case of Base-Selective Transformation, J. Org. Chem., 2016, 81, 1378-1390.

9 (a) V. A. Soloshonok, Y. N. Belokon, N. A. Kuzmina, V. I. Maleev, N. Y. Svistunova, V. A. Solodenko and V. P. Kukhar, Asymmetric synthesis of phosphorus analogues of dicarboxylic $\alpha$-amino acids, J. Chem. Soc. Perkin Trans., 1992, 1, 1525-1529; (b) W. Zhang, W. Sha, R. Pajkert, H. Mei, Y. Pan, J. Han, G.-V. Röschenthaler and V. A. Soloshonok, $\beta$-Amino- $\gamma$, 
-difluoro- $\omega$-phosphonoglutamic Acid Derivatives: An Unexplored, Multifaceted Structural Type of Tailor-Made $\alpha$ Amino Acids, Eur. J. Org. Chem. 2017, 3451-3456; (c) C. Xie, L. Zhang, H. Mei, R. Pajkert, M. Ponomarenko, Y. Pan, G.-V. Röschenthaler, V. A. Soloshonok and J. Han, New Chiral Reagent for Installation of Pharmacophoric (S)- or $(R)$-2(Alkoxyphosphono)-1-amino-2,2-difluoroethyl Groups, Chem Eur. J., 2016, 22, 7036-7040; (d) M. Kwiatkowska, M. Marcinkowska, A. Wzorek, R. Pajkert, J. Han, K. D. Klika, V. A. Soloshonok and G. V. Röschenthaler, The selfdisproportionation of enantiomers (SDE) via column chromatography of $\beta$-amino- $\alpha, \alpha$-difluorophosphonic acid derivatives, Amino Acids, 2019, 51, 1377-1385.

10 (a) A. Bouet, M. Cieslikiewicz, K. Lewinski, G. Coudert and I. Gillaizeau, Acyclic ene-carbamate. A useful tool for an original synthesis of phosphine-containing $\alpha$-amino acids bearing a quaternary carbon, Tetrahedron, 2010, 66, 498-503. (b) M. Cieslikiewicz, A. Bouet, S. Jugé, M. Toffano, J. Bayardon, C. West, K. Lewinski and I. Gillaizeau, P-C Cross-Coupling Onto Enamides: Versatile Synthesis of $\alpha$-Enamido Phosphane Derivatives, Eur. J. Org. Chem. 2012, 6, 1101-1106; (c) C. West, M. Cieślikiewicz-Bouet, K. Lewinski and I. Gillaizeau, Enantiomeric separation of original heterocyclic organophosphorus compounds in supercritical fluid chromatography, Chirality 2013, 25, 230-237.

11 For large-scale preparation of the chiral ligands, see: (a) T. T. Romoff, A. B. Palmer, N. Mansour, C. J. Creighton, T. Miwa, Y. Ejima, H. Moriwaki and V. A. Soloshonok, Scale-up Synthesis of $(R)$ - and (S)-N-(2-Benzoyl-4-chlorophenyl)-1-(3,4dichlorobenzyl)pyrrolidine-2-carboxamide Hydrochloride, A Versatile Reagent for the Preparation of Tailor-Made $\alpha$ - and $\beta$-Amino Acids in an Enantiomerically Pure Form, Org. Process Res. Dev., 2017, 21, 732-739; (b) T. T. Romoff, B. G. Ignacio, N. Mansour, A. B. Palmer, C. J. Creighton, H. Abe, H. Moriwaki, J. Han, H. Konno and V. A. Soloshonok, Large-Scale Synthesis of the Glycine Schiff Base Ni(II) Complex Derived from (S)- and (R)-N-(2-Benzoyl-4-chlorophenyl)-1-[(3,4dichlorophenyl)methyl]-2-pyrrolidinecarboxamide, Org. Process Res. Dev., 2020, 24, 294-300.

12 (a) Y. Tokairin, Y. Shigeno, J. Han, G.-V. Röschenthaler, H Konno, H. Moriwaki and V. A. Soloshonok, Asymmetric Synthesis of 4,4-(Difluoro)glutamic Acid via Chiral Ni(II)Complexes of Dehydroalanine Schiff Bases. Effect of the Chiral Ligands Structure on the Stereochemical Outcome, ChemistryOpen, 2020, 9, 93-96 and ref. 22-23 and 26-27 cited therein; (b) Y. Tokairin, V. A. Soloshonok, H. Konno, H. Moriwaki and G.-V. Röschenthaler, Convenient synthesis of racemic 4,4-difluoro glutamic acid derivatives via Michaeltype additions of $\mathrm{Ni}(\mathrm{II})$-complex of dehydroalanine Schiff bases, J. Fluor. Chem., 2019, 227, 109376.

13 For reviews covering the chemistry and applications of $\mathrm{Ni}(\mathrm{II})$ complexes of AAs, see: (a) J. L. Aceña, A. E. Sorochinsky and V. Soloshonok, Asymmetric synthesis of $\alpha$-amino acids via homologation of $\mathrm{Ni}(\mathrm{II})$ complexes of glycine Schiff bases. Part 3: Michael addition reactions and miscellaneous transformations, Amino Acids, 2014, 46, 2047-2073; (b) Y. Wang, X. Song, J. Wang, H. Moriwaki, V. A. Soloshonok and H. Liu, Recent approaches for asymmetric synthesis of $\alpha$-amino acids via homologation of $\mathrm{Ni}$ (II) complexes, Amino Acids, 2017, 49, 1487-1520; (c) Y. Zou, J. Han, A. S. Saghyan, A. F. Mkrtchyan, H. Konno, H. Moriwaki, K. Izawa and V. A. Soloshonok, Asymmetric Synthesis of Tailor-Made Amino Acids Using Chiral Ni(II) Complexes of Schiff Bases. An Update of the Recent Literature, Molecules, 2020, 25, 2739.

14 See ref. $5 a$ and ref. 18-21 cited therein.

15 Z. Huang, W. Liu, S. Li, Y. Yang, S. Guo and H. Cai, Potassium Carbonate Promoted Nucleophilic Addition of Alkenes with Phosphites, Synlett, 2020, 31, 1295-1297.
16 Y. Nian, J. Wang, S. Zhou, S. Wang, H. Moriwaki, A Kawashima, V. A. Soloshonok and H. Liu, Recyclable Ligands for the Non-Enzymatic Dynamic Kinetic Resolution of Challenging a-Amino Acids, Angew. Chem. Int. Ed., 2015, 54, 12918-12922.

17 Y. Nian, J. Wang, H. Moriwaki, V. A. Soloshonok and H. Liu, Analysis of crystallographic structures of $\mathrm{Ni}$ (ii) complexes of $\alpha$ amino acid Schiff bases: elucidation of the substituent effect on stereochemical preferences, Dalton Trans. 2017, 46, 41914198. 